\title{
Carbon Erosion and Deposition on the ASDEX Upgrade Divertor Tiles
}

\author{
M. Mayer ${ }^{\mathrm{a}}$, V. Rohde ${ }^{\mathrm{a}}$, J. Likonen ${ }^{\mathrm{b}}$, E. Vainonen-Ahlgren ${ }^{\mathrm{b}}$, \\ K. Krieger ${ }^{\mathrm{a}}$, X. Gong ${ }^{\mathrm{a}}$, J. Chen ${ }^{\mathrm{a}}$, and ASDEX Upgrade Team, \\ a Max-Planck-Institut für Plasmaphysik, EURATOM Association, Boltzmannstr. 2, \\ D-85748 Garching, Germany \\ ${ }^{\mathrm{b}}$ VTT Processes, Association EURATOM/TEKES, P.O. Box 1608, FIN-02044 \\ VTT, Finland
}

\begin{abstract}
Carbon deposition and erosion were measured on ASDEX Upgrade divertor tiles and below the roof baffle during the operation period 2002/2003. The inner divertor is a net carbon deposition area, while a large fraction of the outer divertor is erosion dominated and the roof baffle tiles show a complicated distribution of erosion and deposition areas. In total, $43.7 \mathrm{~g} \mathrm{~B}+\mathrm{C}$ were redeposited, of which $88 \%$ were deposited on tiles and $9 \%$ in remote areas (below roof baffle, on vessel wall structures). $0.6 \mathrm{~g}$ $\mathrm{C}$ was pumped out as volatile hydrocarbon molecules. Carbon sources in the main chamber are too low by a factor of more than ten to explain the observed carbon divertor deposition. Carbon erosion is observed at the outer divertor strike point tiles, but it is arguable if material can be transported from the outer strike point to the inner divertor.
\end{abstract}

JNM keywords: Carbon, Divertor Materials, Plasma-Materials Interaction, Redeposition, Surface Effects

PSI keywords: ASDEX-Upgrade, Co-deposition, Divertor material, Erosion \& Deposition, Impurity transport

PACS: 52.40.Hf; 52.55.Fa; 82.80.Yc; 82.80.Ms

Corresponding author: M. Mayer, Max-Planck-Institut für Plasmaphysik, Boltzmannstr. 2, D-85748 Garching, Germany, Matej.Mayer@ipp.mpg.de

Presenting author: M. Mayer, Matej.Mayer@ipp.mpg.de

\section{Introduction}

Major disadvantages of carbon as plasma facing material are its high chemical erosion yield by hydrogen bombardment $[1,2]$, and its ability to trap large 
amounts of hydrogen by codeposition [3]. It has been shown previously at JET and ASDEX Upgrade, that carbon is eroded in the main chamber and redeposited preferentially in the inner divertor $[4,5,6,7,8]$. Increasing coverage of the ASDEX Upgrade walls with tungsten allows a more detailed identification of remaining carbon erosion areas. Carbon limiters at the low field side were identified as carbon sources, from where about $3 \times 10^{19} \mathrm{C}$-atoms/s are eroded $[4,5,6]$. The tungsten coated inner heat shield serves as carbon recycling area $[4,5]$. Carbon deposition on some ASDEX Upgrade divertor tiles was studied by secondary ion mass spectrometry (SIMS), resulting in a deposition of about $15 \times 10^{19} \mathrm{C}$-atoms/s [5]. This is about five times larger than the main chamber carbon source. Although these numbers are based on only few data points and are subject to large errors, they indicate either the existence of additional carbon sources, or much larger experimental errors than assumed by the experimentalists.

Data about net carbon erosion are scarce due to the experimental difficulties of erosion measurements. Carbon erosion/deposition was studied in some detail at the TEXTOR limiter [9], and there is some indication about net carbon erosion in the outer divertors of JET and DIII-D $[8,10]$. This paper presents data about integrated carbon erosion/deposition in the ASDEX Upgrade divertor, based on more than 200 data points measured post mortem with quantitative ion beam analysis methods and SIMS.

\section{Experimental}

The ASDEX Upgrade divertor IIb is shown in Fig. 1. Tiles $6 \mathrm{~A}$ and $6 \mathrm{~B}$ form the inner baffle, tiles 9A, 9B and $9 \mathrm{C}$ the roof baffle, and tiles 2 and 3 the outer baffle. Tile 4 is the inner strike point tile, and tiles $1_{\text {low }}$ and $1_{\text {up }}$ the outer strike point tiles. Most tiles consist of fine grain graphite from Ringsdorff, while tile 4 is made from carbon-fibre composite (CFC), type N11 from SEP. All tiles 6A and $6 \mathrm{~B}$ were coated with $\mathrm{W}$ using physical vapor deposition (PVD) in summer 2002, except the two tiles used for this analysis.

A poloidal section of tiles in sector 12 was coated with a marker consisting of $1.6 \times 10^{18}$ Re-atoms $/ \mathrm{cm}^{2}$ (about $230 \mathrm{~nm}$ ), and $3.1 \times 10^{19}$ (about $3.1 \mu \mathrm{m}^{1}$ ) carbon on top using a pulsed plasma arc [11]. The outer strike point tiles $1_{\text {low }}$ and $1_{\text {up }}$ were covered with a thicker carbon layer of $7.5 \times 10^{19}$ (about $7.5 \mu \mathrm{m}$ ). The marker layer width was $15 \mathrm{~mm}$. The Re serves as marker for ion beam analysis and SIMS, allowing to measure the thickness of the overlaying carbon layer.

$\overline{1}$ For simplicity we use a carbon density of $1 \times 10^{23}$ at $/ \mathrm{cm}^{3}=2 \mathrm{~g} / \mathrm{cm}^{3}$ throughout this paper. 


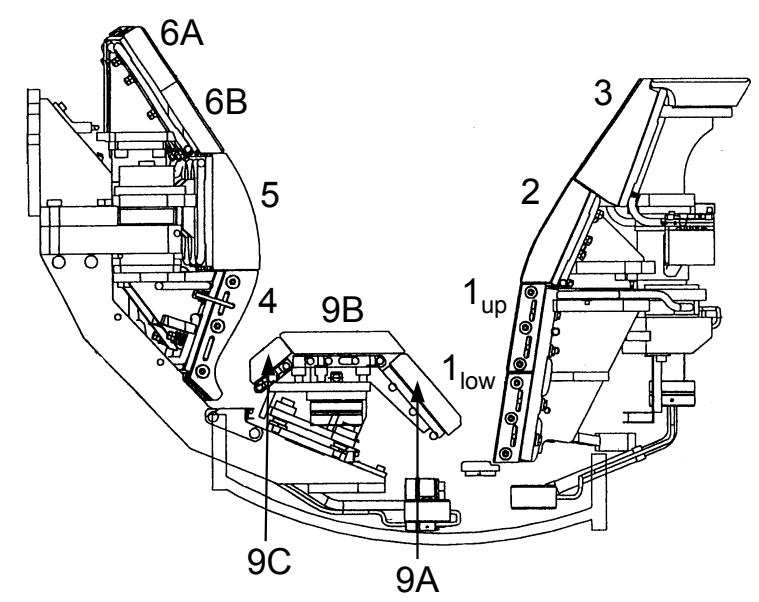

Fig. 1. ASDEX Upgrade divertor IIb. Numbers indicate tile numbers.

The tiles were analyzed prior to installation with Rutherford-backscattering (RBS) using $1.6 \mathrm{MeV}$ protons at $165^{\circ}$. The coatings were homogeneous with a thickness variation of less than $5 \%$ on most tiles.

The tiles were analyzed again after exposure using RBS under the same conditions. For thicker layers $2.5 \mathrm{MeV}$ protons were used. The information depth is about $13 \mu \mathrm{m}$ for $1.6 \mathrm{MeV}$ protons, and about $26 \mu \mathrm{m}$ at $2.5 \mathrm{MeV}$. Deuterium was detected using nuclear reaction analysis (NRA) using 0.8 and $2.5 \mathrm{MeV}$ ${ }^{3} \mathrm{He}$, having information depths of 1.3 and $8 \mu \mathrm{m}^{2}$. The spectra were evaluated with the program SIMNRA $[12,13,14]$.

Secondary ion mass spectrometry (SIMS) measurements were performed using a scanned beam of $5 \mathrm{keV} \mathrm{O}_{2}^{+}$[15]. The depth calibration was obtained by measuring the SIMS crater depth with a profiler.

The tiles were installed in 11/2002 and replaced in 08/2003. 1237 plasma discharges with $4944 \mathrm{~s}$ plasma in divertor configuration were performed during the discharge period. Six boronizations and one siliconization were applied during this time for wall conditioning. The siliconization was performed 2 weeks (about 150 discharges) before the end of the discharge period.

\section{Results and discussion}

The strike point position during the discharge period is shown in Fig. 2 (top). The s-coordinate is measured along the tile surfaces. The inner strike point was mostly on tile 4 (integrated discharge time $4638 \mathrm{~s}$ ), the outer strike point

$\overline{2}$ These depths are for pure carbon. The information depths are larger by about $50 \%$ in deuterium-rich hydrocarbon layers with $\mathrm{D} / \mathrm{C} \approx 1$. 

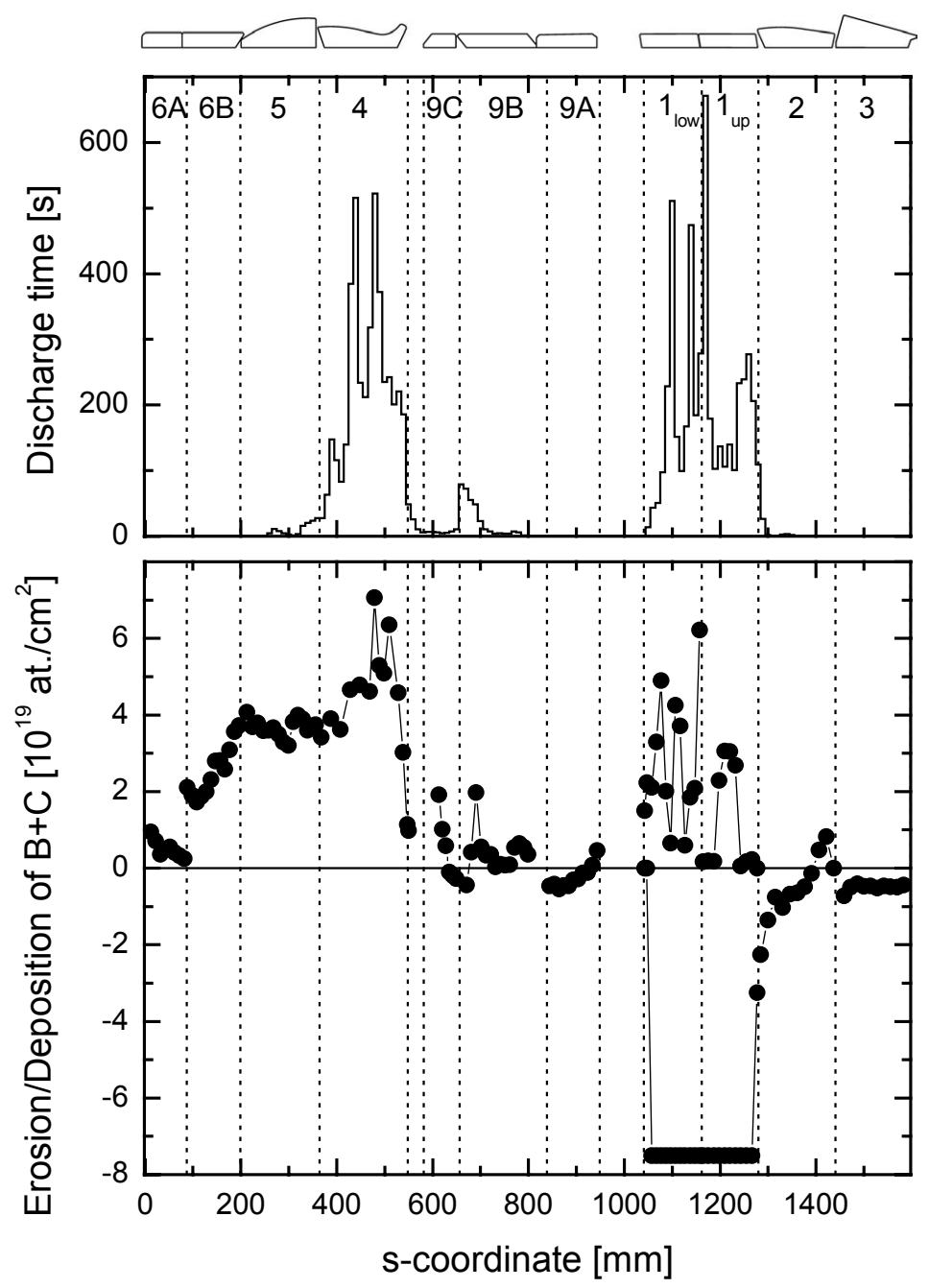

Fig. 2. Top: Distribution of strike point positions (from magnetic reconstruction) during the discharge period 2002/2003 together with a schematic representation of the tiles. Histogram width $10 \mathrm{~mm}$. Bottom: Carbon erosion and deposition of boron + carbon on the divertor tiles, as measured with RBS. At the outer strike point tiles $1_{\text {low }}$ and $1_{\text {up }}$ both erosion and deposition are observed in some areas.

was on tiles $1_{\text {low }}$ and $1_{\text {up }}$. Some discharges had their strike point on roof baffle tile $9 \mathrm{~B}$, the integrated time for this configuration was $306 \mathrm{~s}$.

Net deposition and erosion of boron + carbon on the tiles is shown in Fig. 2 (bottom). The sum of $\mathrm{B}+\mathrm{C}$ can be determined accurately with RBS from the energy shift of the Re peak, but the discrimination of both elements is difficult due to overlap of the sub-spectra. The $\mathrm{B} / \mathrm{C}$ ratio in redeposited layers could be determined only close to the surface of sufficiently thick layers, where it was in the range 0.1-0.2. Boron originates from regular boronizations for wall conditioning [16], during which about $60 \mathrm{~nm}$ of amorphous hydrogen-boron layer are deposited on the main chamber walls. Only small amounts are deposited in the divertor due to the closed geometry. From the walls it is subsequently 
eroded and redeposited in the divertor. Small amounts of silicon are visible at the surface due to the siliconization, and oxygen is present at a level of 5-15 at\%. Other elements like Fe and $\mathrm{W}$ are detected only in small quantities $\left(2-7 \times 10^{16}\right.$ atoms $/ \mathrm{cm}^{2}$ for $\mathrm{Fe},<2 \times 10^{16}$ atoms $/ \mathrm{cm}^{2}$ for $\left.\mathrm{W}\right)$. The amount of $\mathrm{D}$ depends on the temperature history of the tile, and varies from $1 \times 10^{17} \mathrm{at} / \mathrm{cm}^{2}$ at the outer baffle and part of the outer strike point tiles, to $4.7 \times 10^{19} \mathrm{at} / \mathrm{cm}^{2}$ at the inner strike point tile, where deuterium rich layers with $\mathrm{D} / \mathrm{C}$ close to 1 are observed. The absolute accuracy of layer thickness measurements is about $10 \%$. The accuracy of erosion/deposition measurements is better, because several errors cancel out, and is about $1 \times 10^{18}$ atoms $/ \mathrm{cm}^{2}$ (about $100 \mathrm{~nm}$ ).

The whole inner divertor is a net carbon deposition area. The thickest deposits are observed on tile 4 , but tile 5 and a fraction of tile $6 \mathrm{~B}$ show also thick deposits, although the strike point was never on these tiles. Tile $6 \mathrm{~A}$ shows only smaller deposits.

A complicated distribution of net deposition and erosion areas is observed on the roof baffle. Tile $9 \mathrm{C}$ shows deposition at the surface facing the inner strike point. Deposition is also observed on tile $9 \mathrm{~B}$ in the region of the roof baffle strike point position. Some erosion is observed on tile 9A, followed by small deposition just opposite the outer strike point. In total, the effects on the roof baffle tiles are small, compared to the inner and outer divertor.

The outer baffle (tiles 2 and 3 ) is a net carbon erosion area, and the erosion ranges from $0.5-2.5 \mu \mathrm{m}$. Deposition is observed in areas shadowed by neighboring tiles, like the area on tile 2 close to tile $3(\mathrm{~s}=1400-1440 \mathrm{~mm})$. Boron and carbon deposition is also observed on a small fraction of the bottom part of tile $1_{\text {low }}(\mathrm{s}=1040-1050 \mathrm{~mm})$, where the strike point was never positioned. Hydrocarbon layers with $\mathrm{D} / \mathrm{C} \approx 1$ are observed here. The outer strike point area on tiles $1_{\text {low }}$ and $1_{\text {up }}$ shows strong erosion, and the whole initial carbon and a large fraction $(>90 \%)$ of the Re marker layer have disappeared on most of the tile surface, i.e. the erosion exceeds $7.5 \mu \mathrm{m}$ carbon. The Re marker was still present in the deposition area on the bottom part of tile $1_{\text {low }}$, and on a small fraction of tile $1_{\text {up }}$ close to tile $2(\mathrm{~s}=1280 \mathrm{~mm})$ : In this area the initial carbon layer thickness decreased from 6.8 to $3.7 \mu \mathrm{m}$. But in some areas of tiles $1_{\text {low }}$ and $1_{\text {up }}$ not only erosion, but also deposition up to $6 \mu \mathrm{m}$ is observed, especially at $\mathrm{s}=1077 \mathrm{~mm}, 1110 \mathrm{~mm}, 1160 \mathrm{~mm}, 1200-1230 \mathrm{~mm}$. Erosion can be concluded from the disappearance of about $90 \%$ of the original Re marker, as was determined with RBS and SIMS (see below), while deposition can be concluded from the depth profiles of oxygen and boron: These elements were observed up to depths of several $\mu \mathrm{m}$ in some areas, although the initial carbon layer and the Re marker were eroded. This was confirmed qualitatively with scanning electron microscopy (SEM), where deposited layers were observed in some areas $(\mathrm{s}=1077 \mathrm{~mm}, 1110 \mathrm{~mm}, 1160 \mathrm{~mm}, 1200-1230 \mathrm{~mm})$. In areas without additional deposition, the SEM images confirmed net erosion. This 


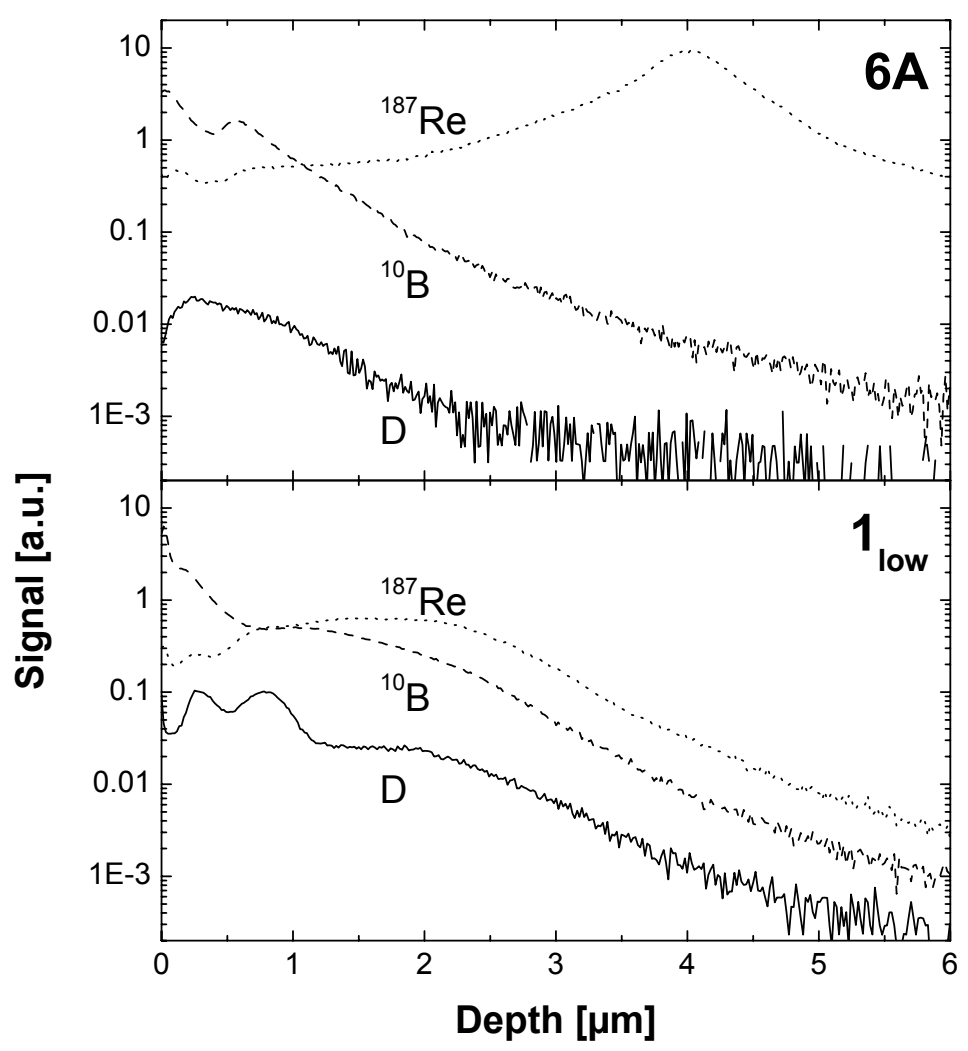

Fig. 3. SIMS depth profiles for $\mathrm{D},{ }^{10} \mathrm{~B}$, and ${ }^{187}$ Re. The signals are relative to the ${ }^{12} \mathrm{C}$ signal. Top: Tile $6 \mathrm{~A}$ at $\mathrm{s}=12.2 \mathrm{~mm}$; bottom: Tile $1_{\text {low }}$ at $\mathrm{s}=1099.5 \mathrm{~mm}$.

additional deposition is correlated with the strike point position, see Fig. 2: Often used strike point positions show no or only small deposits, while thicker deposits are observed on areas in-between.

SIMS depth profiles of D, B, and Re are shown in Fig. 3 for tiles $6 \mathrm{~A}$ and $1_{\text {low }}$. On tile $6 \mathrm{~A}, \mathrm{D}$ and $\mathrm{B}$ are observed in a redeposited layer with a thickness of about $0.8 \mu \mathrm{m}$. The initial Re layer is observed in a depth of about $4 \mu \mathrm{m}$ below the initial carbon layer and the deposit. These depth profiles are in good agreement with RBS measurements at the same position, where a total layer thickness of $4.1 \times 10^{19}$ atoms $/ \mathrm{cm}^{2}(4.1 \mu \mathrm{m})$, consisting of $3.2 \times 10^{19}$ atoms $/ \mathrm{cm}^{2}$ $(3.2 \mu \mathrm{m})$ initial carbon layer and $0.9 \times 10^{19}$ atoms $/ \mathrm{cm}^{2}(0.9 \mu \mathrm{m})$ redeposited layer on top, are observed above the Re-layer. The large width of the Re signal in the SIMS profile is due to surface roughness. On tile $1_{\text {low }}, \mathrm{D}$ and $\mathrm{B}$ are observed up to a depth of about $1 \mu \mathrm{m}$. Re is observed between the surface and a depth of about $3 \mu \mathrm{m}$. Initially, the Re was covered by a layer of $7.8 \mu \mathrm{m}$ carbon, which has been eroded. RBS measurements at the same position show, that only about $5-10 \%$ of the initial amount of Re are still present.

Total amounts of redeposited $\mathrm{B}+\mathrm{C}$ and eroded $\mathrm{C}$ are summarized in Table 1 . Carbon is mainly redeposited in the inner divertor and on roof baffle tile $9 \mathrm{C}$. Some additional carbon deposition is observed below the roof baffle and 
Table 1

Carbon balance for the discharge period 2002/2003. Inner divertor summarizes erosion/deposition on tiles 4-6B, roof baffle summarizes tiles $9 \mathrm{~A}-9 \mathrm{C}$, and outer divertor summarizes tiles $1_{\text {low }}$ to 3 . Below roof baffle + vessel summarizes the areas below the roof baffle, the vessel area below the roof baffle, pump ducts, and the $\mathrm{LN}_{2}$-shield of the cryogenic pump.

\begin{tabular}{lcc}
\hline & Erosion of C & Deposition of B+C \\
& $\mathrm{g}$ & $\mathrm{g}$ \\
\hline Inner divertor & 0 & 27.3 \\
Roof baffle & -0.6 & 2.9 \\
Outer divertor & $<-38.3$ & 9.5 \\
Behind inner heat shield $[18]$ & 0 & 0.4 \\
Below roof baffle + vessel $[18]$ & 0 & 3.6 \\
Pumped out [5] & 0 & 0.6 \\
Outboard main chamber limiter[5,6] & -2.6 & $?$ \\
\hline Total & $<\mathbf{- 4 1 . 5}$ & $\mathbf{4 4 . 3}$ \\
\hline
\end{tabular}

other remote wall areas, where hydrocarbon layers with $\mathrm{D} / \mathrm{C} \approx 1$ are observed $[17,18,19]$. But these amounts are small compared to the deposition on the inner divertor tiles. Deposition is also observed in some areas of the outer divertor, but this is more than counterbalanced by erosion at the outer baffle and outer strike point, resulting in a strong net erosion in the outer divertor. Due to total erosion of the carbon marker layer only a lower bound for the erosion can be given. Erosion from the main chamber outboard limiters was determined spectroscopically during the 2001/2002 campaign and extrapolated to the $2002 / 2003$ campaign investigated in this work. Additionally, there is is a total flux of $11.5 \mathrm{~g}$ carbon originating from the inner heat shield $[4,5,6]$. However, as the inner heat shield is coated with tungsten, this carbon influx is not a primary carbon source, but has been interpreted as carbon recycling $[4,5]$.

The amounts of eroded and redeposited carbon in Table 1 suggest, that the outer divertor is the major carbon source. Carbon is then subsequently transported to the inner divertor, where it is redeposited. Carbon limiters in the main chamber act as additional carbon sources, but their source strength is lower by a factor of more than ten compared to the outer divertor. However, this interpretation should be taken with some care, because

(1) The thermal conductivity of the used marker layers is lower than that of the tiles. This may result in higher surface temperatures and increased chemical erosion yields, thus overestimating tile erosion. However, as the temperature dependence of the chemical erosion yield is small for ion 
energies below $50 \mathrm{eV}[2]$, this should result in differences of less than a factor of two.

(2) The marker layers could have been lost due to mechanical failure (delamination) instead of erosion. The surface was investigated thoroughly with a scanning electron microscope (SEM), and the SEM micrographs gave no indication of mechanical failure, but instead showed clearly net erosion of the tiles at least in some areas. Nevertheless, loss of the marker layers due to delamination cannot be excluded completely.

(3) ${ }^{13} \mathrm{CH}_{4}$ puff experiments in the outer divertor of ASDEX Upgrade gave no indication of carbon transport to the inner divertor, but all carbon was deposited close to the puff hole [20].

(4) Carbon influx from the outboard limiters has been measured in the flat top phase of selected discharges [6], which may be not representative and underestimate the carbon influx from the limiters.

Despite these uncertainties, it can be concluded that carbon erosion occurs in the outer divertor. This erosion is at least equivalent, if not exceeding, carbon erosion in the main chamber. Whether eroded carbon is subsequently transported from the outer to the inner divertor, is an open question. At least the ${ }^{13} \mathrm{CH}_{4}$ puff experiments in the outer divertor give no indication for long range transport, but point towards local redeposition.

Erosion/deposition in the ASDEX Upgrade divertor was studied during the tungsten divertor experiment with divertor I in 1995/1996. The divertor strike point tiles were coated with $\mathrm{W}$, while inner main chamber walls and outboard limiters consisted of carbon. Tungsten erosion was observed at the outer strike point, while carbon was deposited in the inner divertor [21,22]. Carbon originated from the main chamber. The outer divertor tungsten erosion was not quantified, while carbon deposition was comparable (within a factor of two) to the inner divertor deposition observed in this work. The detailed location of carbon sources was not investigated, but it can be assumed that carbon originated mainly from the inner wall: Even after coating of the inner wall with $\mathrm{W}$, the carbon fluxes from the inner wall are larger than from the outboard limiters [6]. Therefore, carbon fluxes during the tungsten divertor experiment and the present situation may be not directly comparable: The divertor geometry was changed considerably, the primary carbon source at the inner wall was eliminated by coating with $\mathrm{W}$, and an additional carbon source in the outer divertor was added.

It was concluded for the DIII-D divertor, that partially detached plasmas have net deposition near the outer strike point, while attached plasmas have net erosion at the outer strike point [10]. However, this conclusion cannot be transferred directly to ASDEX Upgrade due to the different divertor geometry, and a smaller amount of main chamber carbon sources due to increasing coverage with W. 
Additional measurements, which might clarify the puzzle, are foreseen for the discharge period 2004/2005.

\section{Conclusions}

For the first time both carbon deposition and carbon erosion were measured on ASDEX Upgrade divertor tiles and below the divertor roof baffle. The inner divertor is a net carbon deposition area, while a large fraction of the outer divertor is erosion dominated and the roof baffle tiles show only minor effects. The $\mathrm{B}+\mathrm{C}$ deposition on divertor tile surfaces is about 10 times larger than in remote areas like below the roof baffle, vessel wall structures and pump ducts. Major carbon sources in the main chamber are carbon limiters at the outboard side. However, carbon erosion from these limiters is lower by a factor of more than 10 compared to carbon deposition. Large carbon erosion is observed at the outer divertor strike point tiles and the outer baffle, indicating that the outer strike point tiles are the major net carbon source in ASDEX Upgrade, exceeding the main chamber source by a factor of more than 10. However, as the applied marker technique might give incorrect results at high thermal loads and ${ }^{13} \mathrm{CH}_{4}$ puff experiments gave no indication for carbon transport from the outer to the inner divertor, the carbon balance and carbon transport in ASDEX Upgrade remains unclear and require additional measurements.

\section{Acknowledgements}

Ion beam analysis measurements by T. Utikal and the technical assistance of J. Dorner and M. Fußeder are gratefully acknowledged.

\section{References}

[1] E. Vietzke and A.A. Haasz. Chemical erosion. In Physics of Plasma-Wall Interactions in Controlled Fusion, W. Hofer and J. Roth, Eds. Academic Press, San Diego, New York, Boston, London, Sydney, Tokyo, Toronto, 1996, p. 135.

[2] M. Balden and J. Roth. J. Nucl. Mater. 280 (2000) 39.

[3] M. Mayer, V. Philipps, P. Wienhold, H.G. Esser, J. von Seggern, and M. Rubel. J. Nucl. Mater. 290-293 (2001) 381.

[4] M. Mayer, V. Rohde, T. Pütterich, P. Coad, P. Wienhold, JET-EFDA contributors, and ASDEX Upgrade Team. Physica Scripta T111 (2004) 55. 
[5] V. Rohde, R. Dux, M. Mayer, R. Neu, T. Pütterich, R. Pugno, W. Schneider, and the ASDEX Upgrade Team. Physica Scripta T111 (2004) 49.

[6] T. Pütterich, R. Dux, J. Gafert, A. Kallenbach, R. Neu, R. Pugno, S.W. Yoon, and ASDEX Upgrade Team. Plasma Phys. Controlled Fusion 45 (2003) 1873.

[7] J.P. Coad, N. Bekris, J.D. Elder, S.K. Erents, D.E. Hole, K.D. Lawson, G.F. Matthews, R-D. Penzhorn, and P.C. Stangeby. J. Nucl. Mater. 290-293 (2001) 224.

[8] J.P. Coad, P. Andrew, D.E. Hole, S. Lehto, J. Likonen, G.F. Matthews, M. Rubel, and Contributors to the EFDA-JET work-programme. J. Nucl. Mater. 313-316 (2003) 419.

[9] M. Mayer, P. Wienhold, D. Hildebrandt, and W. Schneider. J. Nucl. Mater. 313-316 (2003) 377.

[10] D.G. Whyte, R. Bastasz, J.N. Brooks, W.R. Wampler, W.P. West, C.P.C. Wong, O.I. Buzhinskij, and I. V. Opimach. J. Nucl. Mater. 266-269 (1999) 69.

[11] S. Lehto, J. Likonen, J.P. Coad, T. Ahlgren, D.E. Hole, M. Mayer, H. Maier, P. Andrew, and J. Kolehmainen. Fusion Eng. Des. 66-68 (2003) 241.

[12] M. Mayer. SIMNRA user's guide. Tech. Rep. IPP 9/113, Max-Planck-Institut für Plasmaphysik, Garching, 1997.

[13] M. Mayer. SIMNRA, a simulation program for the analysis of NRA, RBS and ERDA. In Proceedings of the 15th International Conference on the Application of Accelerators in Research and Industry (1999), J. L. Duggan and I. Morgan, Eds., vol. 475 of AIP Conference Proceedings, American Institute of Physics, p. 541.

[14] M. Mayer. Nucl. Instr. Meth. B194 (2002) 177.

[15] E. Vainonen-Ahlgren, J. Likonen, T. Renvall, V. Rohde, R. Neu, R. Pugno, K. Krieger, M. Mayer, and ASDEX Upgrade Team. J. Nucl. Mater. (2005) . this conference.

[16] V. Rohde, R. Neu, R. Dux, T. Härtl, H. Maier, J. Luthin, H.G. Esser, V. Philipps, and ASDEX Upgrade Team. Comparison of boronization and siliconization in ASDEX upgrade. In 26th EPS Conference on Controlled Fusion and Plasma Physics (1999), vol. 23J of europhysics conference abstracts, p. 1513.

[17] M. Mayer, V. Rohde, A. von Keudell, and the ASDEX Upgrade Team. J. Nucl. Mater. 313-316 (2003) 429.

[18] V. Rohde, M. Mayer, J. Likonen, R.Neu, R. Pugno, T. Pütterich, E. VainonenAhlgren, and the ASDEX Upgrade Team. J. Nucl. Mater. (2005) . this conference.

[19] V. Rohde, H. Maier, K. Krieger, R. Neu, J. Perchermaier, and ASDEX Upgrade Team. J. Nucl. Mater. 290-293 (2001) 317. 
[20] R. Pugno, A. Kallenbach, J. Likonen, E. Vainonen-Ahlgren, D. Coster, R. Dux, A. Kirschner, K. Krieger, V. Rohde, U. Fantz, and ASDEX Upgrade Team. J. Nucl. Mater. (2005) . this conference.

[21] H. Maier, K. Krieger, M. Balden, J. Roth, and the ASDEX Upgrade-Team. J. Nucl. Mater. 266-269 (1999) 1003.

[22] K. Krieger, H. Maier, R. Neu, and ASDEX Upgrade Team. J. Nucl. Mater. 266-269 (1999) 207. 